\title{
A Causal Analysis of Women Engaging in Commercial Sex
}

\author{
Hee Dae Kim* \\ Department of Public Health, Pusan National University, 2 Busandaehak-ro 63beon-gil, Geumjeong-gu, Busan, South Korea \\ *: All correspondence should be sent to: Dr. Hee Dae Kim. \\ Author's Contact: Hee Dae Kim, PhD, E-mail: heedaekim@gmail.com \\ DOl: https://doi.org/10.15354/si.22.re031 \\ The author declares no competing interest.
}

\begin{abstract}
Female sex workers (FSWs) are women who engage in sexual behavior with others for monetary compensation. The FSW community has comparable demographic characteristics to the overall population, with a focus on youth, low education, and high mobility. Some women engage in sex trafficking on purpose, not to earn money, but to violate social norms. Feminists who grow up in broken or dysfunctional homes have their familial support networks disturbed. Disruptions to the financial support network include forced departures due to financial restrictions, unemployment, and so on. Women's decisions to enter the sector are significantly influenced by peer behavior. Sexual assault may have a detrimental effect on an individual's viewpoint, self-awareness, and emotional capacity. While the majority of FSWs are motivated by economic considerations, a sizable percentage is driven to prostitution. Other women forced into the sex trade have great things to say about it, and when given the opportunity to leave, some opt to stay.
\end{abstract}

Keywords: Female Sex Workers; Causal Analysis; Sexual Behavior; Commercial Sex; Economics

Science Insights, 2022 February 28; Vol. 40, No. 3, pp.451-456.

(c) 2022 Insights Publisher. All rights reserved.

Creative Commons Non Commercial CC BY-NC: This article is distributed under the terms of the Creative Commons Attribution-NonCommercial 4.0 License which permits non-commercial use, reproduction and distribution of the work without further permission provided the original work is attributed by the Insights Publisher.

$\mathrm{F}$ TEMALE sex workers (FSWs) are women who engage in sexual activity with others in exchange for tangible benefits such as money. Prostitutes who give a variety of pornographic services are the objects. The number of FSWs has increased significantly, while the incentives for women to engage in the sex trade have become more diversified as women's social position and sexual views have changed (1). This paper evaluates the causes and probable predisposing factors for FSWs to engage in sex trafficking by doing a literature search on the FSW community in order to provide the groundwork for future relevant research.

\section{Demographic Characteristics}

The demographic features of the FSW population are similar to those of the general population, with an emphasis on youth, poor education, and high mobility. Kramer and Berg studied 309 street FSWs in Arizona, USA, and discovered that they had an average age of 31.5 years and were $54 \%$ single (2). According to the Australian poll, $44 \%$ of respondents are under the age of 30 , and $57 \%$ have a secondary school education or less (3). From 1990 to 2006, the results of behavioral research on FSWs in China revealed that the majority of FSWs were in their teens and twenties, unmarried, unemployed prior to engaging in the sex trade, or grew up in rural regions, and were a floating population (4). According to a survey conducted in Vietnam, more than half of FSWs under the age of 29 work as full-time prostitutes (5). Dandona et al. studied 6,648 FSWs in 13 Indian states and discovered that $75.6 \%$ were between the ages of 20 and $34,74.7 \%$ 
were uneducated, $30.7 \%$ were divorced or separated, and rural women began engaging in sex trafficking (6). The average age of rural women was much younger (21.7 years) than that of urban women (23.9 years). According to a survey conducted in Enugu City, Nigeria, the average age of 135 FSWs was 26.95.5 years, 46.7 percent had only completed elementary school, and 55.6 percent were unmarried (7).

Additionally, FSWs' work hours differ by country and location. Bucardo et al. conducted a study of FSWs in Mexico and discovered that their average tenure was five years (3 months to 14 years) (8). According to a survey in India, 51.3\% of FSWs had been involved in sex trafficking for two to five years (9). About $60.7 \%$ of medium and low-grade FSWs in China had worked for less than two years (10).

\section{Causal Inferences Economic Considerations}

Economic reasons alone, without a doubt, play a significant role in why women participate in prostitution. According to a survey conducted in Denmark, 85\% of FSWs are for financial gain (11). Study conducted in China have revealed that the primary reason women enter the sex trade industry is for financial gain, and poverty and a lack of employment opportunities force them to seek financial gain (4). Around two-thirds of India's 5,498 mobile FSWs are acknowledged to be engaging in sex trading for economic gain (12). In Victoria, Australia, 69\% of women participate in prostitution for financial gain (3). Poverty, for a variety of reasons, can "draw" women into the sex trade, much more so when the trade provides for their survival and is a viable source of income (13-15).

\section{Factors of Employment}

In Africa's Nigeria, $61.2 \%$ of FSWs earn their income through prostitution (16). According to Russian research, the primary reason women enter the sex trade business is a lack of work possibilities (17). In Beijing, China, more than 70\% FSWs earned more than 3,000 CNY per month, whereas more than $70 \%$ of comparison female with the same age, education, and social background earned less than 3,000 CNY per month. As can be shown, participation in the sex service sector delivers a higher rate of return under the same conditions (18).

\section{Attracted}

Many individuals are drawn to entering the sex trade market on their own. Saggurti et al. studied 5,498 mobile FSWs in India and discovered that 9.4 percent of respondents entered the market independently (12). According to a survey conducted by Devine et al., 13\% of FSWs answered unequivocally that they entered the sex service sector for both pleasure and profit (9). They are not talking about sexual pleasures, but lifestyle pleasures such as like-minded men and women congregating in one location where having fun is their primary objective and the experience makes them happy. Ingabire et al. conducted focus groups and in-depth interviews with 70 FSWs in Rwanda, Africa, and discovered that $8.6 \%$ of FSWs entered the sex trade industry due to the lure of commercial sex work, which includes timely financial remuneration, independent economic conditions, and work joy (19). While these women also encountered some de- gree of disruption, their reports indicate that they chose to participate in sex trafficking in part. An interview with 367 FSWs and discovered that $2.5 \%$ of FSWs entered the sex trade sector in order to have sex (20). In Chicago, USA, some women like the job's flexibility and autonomy as well (14).

\section{Cultural Traditions}

Women frequently perform as sex workers in India as a result of religious beliefs and old customs, such as the Indian habit of "slave of the gods". Before they reach puberty, some females become temple dancers and give sexual services for the rest of their lives (21). Blanchard et al. interviewed 1,588 FSWs in India and discovered that $26 \%$ had entered the sex trade business as a result of the "slave of the gods" habit (22). Sex labor related to traditional Indian rituals has become more popular in recent years (23). In Taiwan, contracted teenage FSWs are descended from the cultural history of lower-class families stretching all the way back to the 18th century's early pioneers. When the girl reaches the age of seven, her parents will either sell her directly to a brothel or to an intermediate family, who will then sell her to the brothel. Parents sell their daughters for a variety of reasons, including survival, emergency necessities, and repayment of gambling debts (24)

\section{Being a Victim of Human Trafficking, Coercion, or Deception}

According to certain sources, some women enter the sex profession as a result of compulsion or violence. This is a frequent finding in Indian research and is frequently related to human trafficking (25). In a survey of 1,137 FSWs aged 18-25 in Andhra Pradesh, India, $50.5 \%$ of women joined the sector through human trafficking $(26,27)$. A survey of 580 FSWs in brothels across four western Indian states revealed that $24 \%$ of respondents were trafficked into the profession, with the majority of these women being from neighboring Nepal and Bangladesh (28). Commercial FSWs in four Indian states showed that $17.7 \%$ of FSWs were coerced or misled into engaging in sex work by people they knew or did not know (29). Accordingly, 13\% of FSWs reported being coerced and duped into the sex service sector, with $76 \%$ being duped by people they trusted such as relatives, neighbors, and husbands (30).

\section{Additional Factors}

McClarty et al. (31) noted that some women intentionally participate in sex trafficking not to earn money, but to go against established societal standards. However, even when women are trafficked into the sex service sector, they actively seek better lives and work prospects in cities and other countries, and some women enter the sex trade after being dumped by their lovers and developing a vengeful attitude towards men (32). Hwang and Bedford said that some teens in Taiwan are motivated to enter the sex service by curiosity and risk-taking (24).

\section{Predisposed Factors \\ Disruption of the Familial or Financial Support System \\ Females growing up in a damaged or dysfunctional home setting,} such as single-parent families (parental divorce, parental death, 
or incarceration), broken relationships with parents, or parental desertion, are examples of disruption of family support networks Financial support network disruptions include forced exits owing to financial constraints, unemployment, and so forth. A family's disintegration is frequently followed by an economic catastrophe. For instance, the loss of a significant labor force in a poor family invariably results in financial restrictions; similarly, economic downturns frequently result in family dissolution. Family or economic concerns have persistently dominated the causes of female prostitution, and practically every study on the causes or motives of female prostitution has come to the same result (33).

The results of a focus group discussion and in-depth interviews with 70 FSWs in Rwanda indicated that the majority of women begin their tales with disturbances to their regular lives, implying that familial and financial support disruption is the primary reason women begin sex work (19). In British teenage FSWs, deficiencies in different elements of children's development, such as family breakup, family strife, parental abuse, and neglect, may serve as future motives for girls to participate in sex work (34). Devine et al. conducted a convenience survey of 220 FSWs in a city in India and discovered that $45 \%$ of the individuals were employed for commercial sex to fulfill their own and their families' basic requirements (9). The cited reasons included chronic poverty, parental death, and family desertion, divorce or widowhood, spouse unable to work, spouse addicted to drug usage, and so on.

\section{Network Interpersonal}

Women joining the sex trade for the first time rely heavily on networking (35). Cobbina and Oselin (36) examined the reasons for FSWs entering the industry during their adolescence (18 years old) and adulthood (19 years old) in America and discovered that $40 \%$ of adolescents "formalize" the sex trade, an environment in which they describe growing up and thinking of sex as a normal job. According to a poll conducted in Chicago, USA, peer behavior has a significant impact on women's decisions. When girls often observe individuals around them earning money by selling sex services, they know at an early age that sex trafficking might be a future vocation (14). Personal interviews with 70 FSWs in Rwanda, Africa, revealed that 25 of the study subjects described being exposed to sex trafficking, the majority of whom worked as maids or were dependent on sex workers prior to becoming FSWs. Twenty-eight people stated that they worked in bars where sex trafficking was prevalent, and eight people stated that they had friends and peers who were involved in sex trafficking (19).

\section{Abuse of Substances and Domestic Violence}

Substance abuse is defined here as abuse by a parent or caregiver, a spouse, or one's own drug and alcohol usage. In the United States, $67 \%$ of FSWs grew up in households where one or both parents were addicted to drugs or alcohol (2). Long-term exposure of children to this harmful environment and behavior is detrimental to their physical and mental development. Fifteen percent of women in Nagaland, India, use the sex trade to feed their drug or alcohol addictions (9). Murphy interviewed American street girls and discovered that drug usage was not only a factor in their entry into the profession, but also in their continuing employment (37). Additionally, a study of street FSWs in the United States discovered that $65 \%$ of women who began sex trafficking in adulthood (age 19 and older) cited drug addiction as a motivating factor (36). Domestic abuse is another factor that contributes to women entering the sex profession. About $40 \%$ of married women cited domestic abuse as their primary reason for engaging in sex trafficking, $31 \%$ cited their husband's alcoholic addiction as a cause for being unable or unable to work, and women were forced to labor to earn money (21).

\section{Sexual and Physical Abuse}

Sexual abuse during childhood can damage an individual's perspective, impairing self-awareness and emotional capability. Sexual assault can result in low self-esteem, anxiety, despair, drug misuse, fleeing from home, interpersonal issues, and a variety of other mental and physical disorders that may operate as risk factors for women getting involved in sex trafficking (38). In the United States, studies have revealed that FSWs have a higher prevalence of childhood sexual assault (40\%), and childhood sexual assault appears to be a clear indicator of teenagers involved in sex trafficking. Accordingly, $60 \%$ of women who begin employment as adolescents do so in order to reclaim control of their lives and sexuality. Childhood injuries such as sexual harassment, rape, incest, and physical abuse are quite frequent among these women. Frequently, they opt to flee their homes in order to escape this circumstance (36). In a study of Canadian teenage FSWs and childhood sexual assault, $73 \%$ reported having been sexually assaulted as children, compared to just $29 \%$ of the overall population (39). Sexual abuse in childhood doubles the likelihood of women engaging in sex trafficking compared to women in general (40). Ingabire and colleagues found that almost half of the FSWs polled had suffered sexual or physical abuse (19). Hwang and Bedford examined the variables that influenced Taiwanese teenagers' decision to become FSWs. Among the 49 teenage FSWs, 36 reported experiencing domestic physical abuse, 28 reported experiencing sexual abuse, and $81 \%$ reported experiencing domestic violence on a significant or very serious level (24). Sexual assault and physical abuse violate the victim's body and mind without their will, frequently ruining children's psychological and economic safety nets and putting women in an extremely vulnerable situation.

\section{Delinquent Behavior}

School difficulties (e.g., absenteeism, truancy, fighting, frequently hanging out with undesirable peers, etc.) are referred to as poor conduct, which can eventually result in runaways (41). A study of Japanese high school students discovered a strong correlation between the offering of sexual services and antisocial conduct (42). In addition, while detained for various offences, wayward girls may learn to engage in sex trafficking $(43,44)$. Thirty-one of the 49 adolescent FSWs in Taiwan had a history of smoking and drinking, eleven had a history of drug use, eleven had a history of fighting with classmates, forty-nine were frequently absent from school, twenty-eight were sexually active prior to prostitution, and thirty-three were fleeing home. Running away from home is a critical event that encourages females to engage in the sex trade when they first begin (24). Cobbina 
and Oselin noted that one of the possible motivations for kids to enter the sex trade business is bad school conduct (36). Early sexual abuse and inadequate education might cause girls to flee their homes, and that fleeing increases the likelihood that they will engage in harmful behaviors, such as providing sexual services (45). Compared young FSWs to typical girls with similar living circumstances and environments and discovered that the former were more prone to reporting running away behaviors (46). According to a study of Canadian adolescent FSWs, the primary reasons for their choice to flee home were a need for autonomy and a want to belong (47).

\section{Conclusions}

Economic motivations, work circumstances, being attracted, affected by cultural conventions, being trafficked, coerced, or tricked are the primary reasons for FSW employment. Women may get involved in sex trafficking for a variety of reasons, including disruption of familial or financial support networks, substance misuse, marital violence, exposure to prostitution by others, sexual or physical abuse as a child, and poor academic performance. Due to the fact that factors are strongly linked and intersect, it is difficult to isolate their individual impacts, and the problem of causation is complex. While the majority of FSWs may be exposed to a variety of negative stimuli and influences during their development, such as parental substance abuse, physical violence by caregivers in childhood or domestic violence by husbands after marriage, as well as prostitution and visits by relatives or friends, the impact on women's bodies, psychology, and behavior should not be underestimated. While economic motives play a significant part in why FSWs work, it should be emphasized that owing to the growth of the social economy and the openness of people's beliefs, there are also a large number of individuals drawn to prostitution. Even women who are coerced into the sex trade have some consenting aspects, and when given the option to quit, some women prefer to continue delivering sex.m

\section{References}

1. Silverman JG. Adolescent female sex workers: Invisibility, violence and HIV. Arch Dis Child 2011; 96(5):478-481. DOI: https://doi.org/10.1136/adc.2009.178715

2. Kramer LA, Berg EC. A survival analysis of timing of entry into prostitution: The differential impact of race, educational level, and childhood/adolescent risk factors. Sociol Inq 2003; 73(4):511-528. DOI: https://doi.org/10.1111/1475-682X.00069

3. Bilardi JE, Miller A, Hocking JS, Keogh L, Cummings R, Chen MY, Bradshaw CS, Fairley CK. The job satisfaction of female sex workers working in licensed brothels in Victoria, Australia. J Sex Med 2011; 8(1):116-122. DOI: https://doi.org/10.1111/j.1743-6109.2010.01967.x

4. Hong Y, Li XM. Behavioral studies of female sex workers in China:a literature review and recommendation for future research. AIDS Behav 2008; 12(4):623-636. DOI: https://doi.org/10.1007/s10461007-9287-7

5. Johnston LG, Sabin K, Mai TH, Pham TH. Assessment of respondent driven sampling for recruiting female sex workers in two Vietnamese cities: Reaching the unseen sex worker. J Urban Health 2006; 83(6 Suppl):i16-i28. DOI: https://doi.org/10.1007/s11524-006-9099-5

6. Dandona R, Dandona L, Kumar GA, Gutierrez JP, McPherson S, Samuels F, Bertozzi SM; ASCI FPP Study Team. Demography and sex work characteristics of female sex workers in India. BMC Int Health Hum Rights 2006; 6:5. DOI: https://doi.org/10.1186/1472-698X-6-5

7. Onyeneho NG. HIV/AIDS risk factors and economic empowerment needs of female sex workers in Enugu

Urban, Nigeria. Tanzan J Health Res 2009; 11(3):126-135. DOI: https://doi.org/10.4314/thrb.v11i3.47698

8. Bucardo J, Semple SJ, Fraga-Vallejo M, Davila W, Patterson TL. A qualitative exploration of female sex work in Tijuana, Mexico. Arch Sex Behav 2004; 33(4):343-351. DOI: https://doi.org/10.1023/B:ASEB.0000028887.96873.f 3

9. Devine A, Bowen K, Dzuvichu B, Rungsung R, Kermode M. Pathways to sex-work in Nagaland, India: Implications for HIV prevention and community mobilisation. AIDS Care 2010; 22(2):228-237. DOI: https://doi.org/10.1080/09540120903039869

10. Li Y, Detels R, Lin P, Fu X, Deng Z, Liu Y, Tan Y, Li J, Wu Z. Prevalence of HIV and STIs and associated risk factors among female sex workers in Guangdong Province, China. J Acquir Immune Defic Syndr 2010; 53(Suppl 1):S48-S53. DOI: https://doi.org/10.1097/QAI.0b013e3181c7d72f

11. Karkov R. What drives a prostitute. ScienceNordic.(2012-03-08)[2015-04-20]. Last access: February 28, 2022. Available at: http://sciencenordic.com/what-drives-prostitute

12. Saggurti N, Verma RK, Halli SS, Swain SN, Singh R, Modugu HR, Ramarao S, Mahapatra B, Jain AK. Motivations for entry into sex work and HIV risk among mobile female sex workers in India. J Biosoc Sci 2011; 43(5):535-554. DOI: https://doi.org/10.1017/S0021932011000277

13. Weitzer R. Sociology of sex work. Ann Rev Sociol, 2009; 35(1):213-234. DOI: https://doi.org/10.1146/annurev-soc-070308-120025

14. Rosen E, Venkatesh SA. A "perversion" of choice sex 
work offers just enough in Chicago's urban ghetto. J Contem Ethnogr 2008; 37(4):417-441. DOI: https://doi.org/10.1177/0891241607309879

15. Pueyo A, Maestre M. Linking energy access, gender and poverty: A review of the literature on productive uses of energy. Energy Res Soc Sci 2019; 53:170-181. DOI: https://doi.org/10.1016/j.erss.2019.02.019

16. Onyeneho NG. HIV/AIDS risk factors and economic empowerment needs of female sex workers in Enugu Urban, Nigeria. Tanzan J Health Res 2009; 11(3):126-135. DOI: https://doi.org/10.4314/thrb.v11i3.47698

17. Aral SO, St Lawrence JS, Tikhonova L, Safarova E, Parker KA, Shakarishvili A, Ryan CA. The social organization of commercial sex work in Moscow, Russia. Sex Transm Dis 2003; 30(1):39-45. DOI: https://doi.org/10.1097/00007435-200301000-00009

18. Zhang L, Li X, Wang B, Shen Z, Zhou Y, Xu J, Tang Z, Stanton B. Violence, stigma and mental health among female sex workers in China: A structural equation modeling. Women Health 2017; 57(6):685-704. DOI: https://doi.org/10.1080/03630242.2016.1186781

19. Ingabire MC, Mitchell K, Veldhuijzen N, Umulisa MM, Nyinawabega J, Kestelyn E, Van Steijn M, Van De Wijgert J, Pool R. Joining and leaving sex work: experiences of women in Kigali, Rwanda. Cult Health Sex 2012; 14(9):1037-1047. DOI: https://doi.org/10.1080/13691058.2012.713120

20. Saggurti N, Sabarwal S, Verma R, Halli S, Jain A. Harsh realities:reasons for women's involvement in sex work in India. J AIDS HIV Res 2011; 3(9):172-179.

21. O'Neil J, Orchard T, Swarankar RC, Blanchard JF, Gurav K, Moses S. Dhandha, dharma and disease: traditional sex work and HIV/AIDS in rural India. Soc Sci Med 2004; 59(4):851-860. DOI: https://doi.org/10.1016/j.socscimed.2003.11.032

22. Blanchard JF, O'neil J, Ramesh BM, Bhattacharjee P, Orchard T, Moses S. Understanding the social and cultural contexts of female sex workers in Karnataka, India: implications for prevention of HIV infection. J Infect Dis 2005; 191(Suppl 1):S139-46. DOI: https://doi.org/10.1086/425273

23. Becker ML, Mishra S, Satyanarayana, Gurav K, Doshi M, Buzdugan R, Pise G, Halli S, Moses S, Avery L, Washington RG, Blanchard JF. Rates and determinants of HIV-attributable mortality among rural female sex workers in Northern Karnataka, India. Int J STD AIDS 2012; 23(1):36-40. DOI: https://doi.org/10.1258/ijsa.2011.011017

24. Hwang SL, Bedford O. Precursors and pathways to adolescent prostitution in Taiwan. J Sex Res 2003; 40(2):201-210. DOI: https://doi.org/10.1080/00224490309552181

25. Ghosh B. Trafficking in women and children in India: Nature, dimensions and strategies for prevention. Int J Hum Rig 2009; 13(5):716-738. DOI: https://doi.org/10.1080/13642980802533109

26. George A, Sabarwal S. Sex trafficking, physical and sexual violence, and HIV risk among young female sex workers in Andhra Pradesh, India. Int J Gynaecol Obstet 2013; 120(2):119-123. DOI:

https://doi.org/10.1016/j.ijgo.2012.08.019

27. Reed E, Erausquin JT, Groves AK, Salazar M, Biradavolu M, Blankenship KM. Client-perpetrated and husband-perpetrated violence among female sex workers in Andhra Pradesh, India: HIV/STI risk across personal and work contexts. Sex Transm Infect 2016; 92(6):424-429. DOI:

https://doi.org/10.1136/sextrans-2015-052162

28. Sarkar K, Bal B, Mukherjee R, Chakraborty S, Saha S Ghosh A, Parsons S. Sex-trafficking, violence, negotiating skill, and HIV infection in brothel-based sex workers of eastern India, adjoining Nepal, Bhutan, and Bangladesh. J Health Popul Nutr 2008; 26(2):223-231.

29. Mamulwar M, Godbole S, Bembalkar S, Kamble P, Dulhani N, Yadav R, Kadu C, Kumar P, Lalikar S, Acharya S, Gangakhedkar R, Risbud A, Venkatesh S. Differing HIV vulnerability among female sex workers in a high HIV burden Indian state. PLoS One 2018; 13(2):e0192130. DOI: https://doi.org/10.1371/journal.pone.0192130

30. Evens E, Lanham M, Santi K, Cooke J, Ridgeway K, Morales G, Parker C, Brennan C, de Bruin M, Desrosiers PC, Diaz X, Drago M, McLean R, Mendizabal M, Davis D, Hershow RB, Dayton R. Experiences of gender-based violence among female sex workers, men who have sex with men, and transgender women in Latin America and the Caribbean: a qualitative study to inform HIV programming. BMC Int Health Hum Rights 2019; 19(1):9. DOI: https://doi.org/10.1186/s12914-019-0187-5

31. McClarty LM, Bhattacharjee P, Blanchard JF, Lorway RR, Ramanaik S, Mishra S, Isac S, Ramesh BM, Washington R, Moses S, Becker ML. Circumstances, experiences and processes surrounding women's entry into sex work in India. Cult Health Sex 2014; 16(2):149-163. DOI:

https://doi.org/10.1080/13691058.2013.845692

32. Gerassi L. A heated debate: Theoretical perspectives of sexual exploitation and sex work. J Sociol Soc Welf 2015; 42(4):79-100.

33. Flemming R. Quae Corpore Quaestum Facit: The sexual economy of female prostitution in the Roman Empire. J Roman Stud 1999; 89:38-61. DOI: https://doi.org/10.2307/300733

34. Cusick L. Youth prostitution: A literature review. Child Abuse Rev 2002; 11(4):230-251. DOI: https://doi.org/10.1002/car.743

35. Dalla RL. Et Tú Brutè. A qualitative analysis of streetwalking prostitutes' interpersonal support networks. J Fam Issues 2001; 22(8):1066-1085. DOI: https://doi.org/10.1177/019251301022008006

36. Cobbina JE, Oselin SS. It's not only for the money: An analysis of adolescent versus adult entry into street prostitution. Sociol Inq 2011; 81(3):310-332. DOI: https://doi.org/10.1111/i.1475-682X.2011. 00375.x

37. Murphy LS. Understanding the social and economic contexts surrounding women engaged in street-level prostitution. Issues Ment Health Nurs 2010; 
31(12):775-784. DOI:

https://doi.org/10.3109/01612840.2010.524345

38. Hossain M, Zimmerman C, Abas M, Light M, Watts C. The relationship of trauma to mental disorders among trafficked and sexually exploited girls and women. Am J Public Health 2010; 100(12):2442-2449. DOI: https://doi.org/10.2105/AJPH.2009.173229

39. Bagley C, Young L. Juvenile prostitution and child sexual abuse: A controlled study. Can J Commun Ment Health 1987; 6(1):5-26. DOI: https://doi.org/10.7870/cjcmh-1987-0001

40. Wijkman M, Kleemans E. Female offenders of human trafficking and sexual exploitation. Crim Law Soc Chang 2019; 72; 53-72. DOI: https://doi.org/10.1007/s10611-019-09840-x

41. INSERM Collective Expertise Centre. INSERM Collective Expert Reports [Internet]. Paris: Institut national de la santé et de la recherche médicale; 2000-. Conduct: Disorder in children and adolescents. 2005. Available at: https://www.ncbi.nlm.nih.gov/books/NBK7133/

42. Sakuraba T, Matsui Y, Fukutomi M, Narita K, Kamise Y, Ui M, Kikusuima M. Background factors of amateur prostitution ("enjo-kousai") in Japanese high-school girls. Jpn J Educ Psychol 2001; 49(2):167-174. DOI: https://doi.org/10.5926/jiep1953.49.2 167

43. Schaffer B, DeBlassie RR. Adolescent prostitution. Adolescence 1984; 19(75):689-696.

44. Pasko L. Damaged daughters: The history of girls' sexuality and the juvenile justice system. J Crim Law Criminol 2010; 100(3):1099-1130.

45. Lloyd M. Domestic violence and education: Examining the impact of domestic violence on young children children, and young people and the potential role of schools. Front Psychol 2018; 9:2094. DOI: https://doi.org/10.3389/fpsyg.2018.02094

46. Goldenberg SM, Rangel G, Vera A, Patterson TL, Abramovitz D, Silverman JG, Raj A, Strathdee SA. Exploring the impact of underage sex work among female sex workers in two Mexico-US border cities. AIDS Behav 2012; 16(4):969-981. DOI: https://doi.org/10.1007/s10461-011-0063-3

47. Kitchen P, Williams AM, Gallina M. Sense of belonging to local community in small-to-medium sized Canadian urban areas: A comparison of immigrant and Canadian-born residents. BMC Psychol 2015; 3(1):28. DOI: https://doi.org/10.1186/s40359-015-0085-0

Received: December 18, 2021 ｜ Revised: January 27, 2022 ～Accepted: January 29, 2022 